\title{
A sociolinguistic profile of The Gambia
}

\author{
Kasper Juffermans and Caroline McGlynn
}

\begin{abstract}
This paper outlines the sociolinguistic situation in the smallest country of mainland Africa, The Gambia. Very little has been published about the languages and sociolinguistic situation in The Gambia and it was upon discovering this dearth of reliable published sources that led the authors to pool knowledge garnered during independent doctoral research. In this paper we have coupled language shift with a detailed description of the dynamic sociolinguistic profile of The Gambia and trust that it contributes to an understanding of changing ecologies of language in West Africa. Following a portrayal of the indigenous and exogenous languages of The Gambia, with attention to hybrid, overlapping and shifting ethnolinguistic identities, the role of language in several social institutions in a changing society is identified and discussed. The paper culminates in a discussion of linguistic and cultural diversity and appeals for more research in this sociolinguistically unexposed country.
\end{abstract}

KEYWORDS: THE GAMBIA; WEST AFRICA; MANDINKA; WOLOF; INDIGENOUS LANGUAGES; ENGLISH

\section{Affiliations}

Kasper Juffermans: Department of Language and Culture Studies, Tilburg University, Netherlands. 


\section{Introduction}

The Republic of The Gambia ${ }^{1}$ is the smallest of the mainland African countries and is completely surrounded by Senegal except for a small Atlantic coastline. As depicted in Table 1, The Gambia is divided into five regions (called divisions until recently) and eight local government areas (LGAs). The regions are defined according to the position they take apropos the river Gambia. The LGAs are named after the towns where the administrative head-offices are based and partly overlap with the regions, each of which is further divided into districts.

Apart from the official administrative division, which is a colonial inheritance, there is also a popular division of the country using the names of pre-colonial polities. These pre-colonial states, most of which transcend the current national boundaries, are mainly ancient Mandinka kingdoms and have been the inspiration for the names of the districts: for example Kombo and Foni on the south bank and Niumi and Wuli on the north bank (Sonko-Godwin 2003:8ff). In addition, there are the originally Serer but later Wolof states Sine and Saloum, and Fulladu 'land of the Fula'.

Table 1: Administrative division of The Gambia: 5 regions, 8 LGAs, and 37 districts ${ }^{2}$

\begin{tabular}{|c|c|c|}
\hline Regions & $\begin{array}{l}\text { Local government } \\
\text { areas (LGAs) }\end{array}$ & Districts \\
\hline \multirow{2}{*}{-} & Banjul LGA & Banjul City \\
\hline & Kanifing LGA & Kombo St. Mary/Kanifing Municipality \\
\hline $\begin{array}{l}\text { Western Region } \\
\text { (WR) }\end{array}$ & Brikama LGA & $\begin{array}{l}\text { Kombo North, Kombo South, Kombo Central, } \\
\text { Kombo East, Foni Berefet, Foni Bintang, Foni } \\
\text { Kansala, Foni Bondali, Foni Jarrol }\end{array}$ \\
\hline $\begin{array}{l}\text { Lower River Region } \\
\text { (LRR) }\end{array}$ & Mansakonko LGA & $\begin{array}{l}\text { Kiang West, Kiang Central, Kiang East, Jarra } \\
\text { West, Jarra Central, Jarra East }\end{array}$ \\
\hline $\begin{array}{l}\text { North Bank Region } \\
\text { (NBR) }\end{array}$ & Kerewan LGA & $\begin{array}{l}\text { Lower Niumi, Upper Niumi, Jokadu, Lower } \\
\text { Baddibu, Central Baddibu, Upper Baddibu }\end{array}$ \\
\hline \multirow{2}{*}{$\begin{array}{l}\text { Central River Region } \\
\text { (CRR) }\end{array}$} & Kuntaur LGA & $\begin{array}{l}\text { Lower Saloum, Upper Saloum, Nianija, } \\
\text { Niani, Sami }\end{array}$ \\
\hline & Georgetown LGA & $\begin{array}{l}\text { Niamina Dankunku, Niamina West, Niamina } \\
\text { East, Fulladu West }\end{array}$ \\
\hline $\begin{array}{l}\text { Upper River Region } \\
\text { (URR) }\end{array}$ & Basse LGA & $\begin{array}{l}\text { Fulladu East, Sandu, Wuli West, Wuli East, } \\
\text { Kantora }\end{array}$ \\
\hline
\end{tabular}

In common with many developing countries there is an urban rural dichotomy that dominates the geography and economy of the country. The most urbanised area is located in the Kombo districts on the south bank, and is made up

\section{equinoxonline}




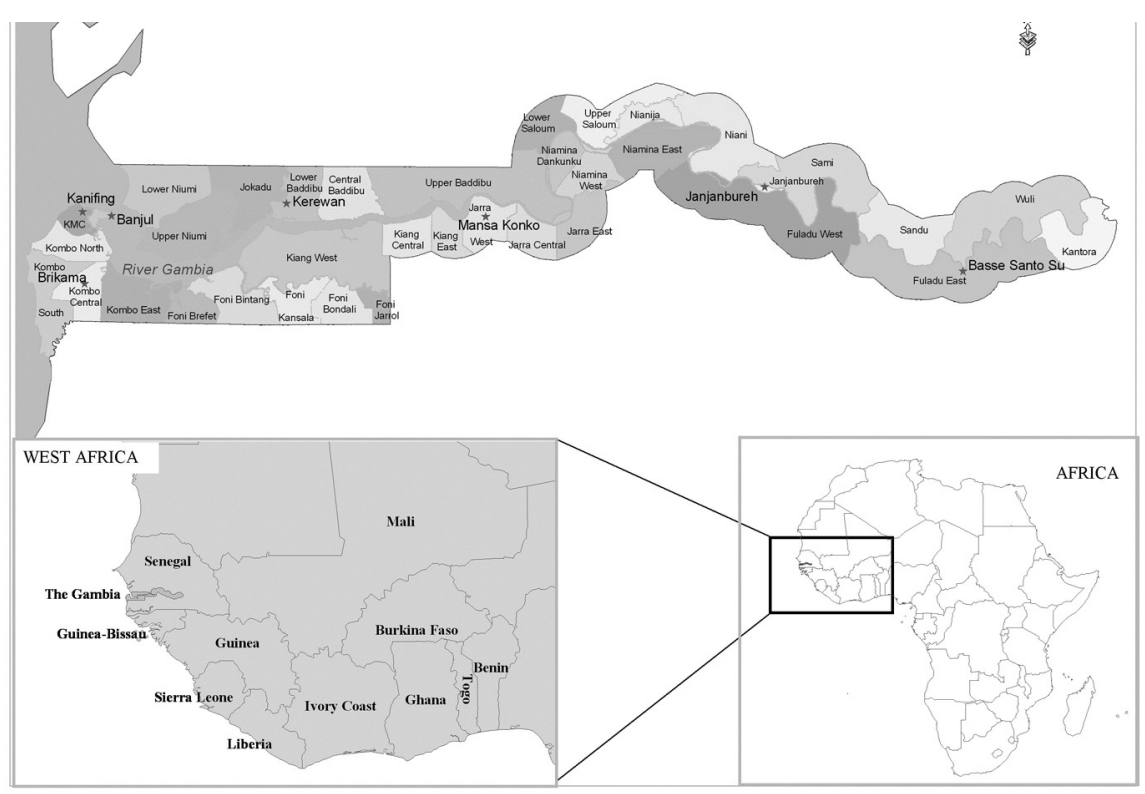

Figure 1: Map of The Gambia and its location in Africa (reproduced with permission from Jaiteh and Saho 2006)

of Banjul, Serrekunda, Kanifing, Bakau, Fajara, Kotu, Kololi, Abuko, Lamin, Yundum and Brikama. The Kombos accommodate the largest proportion of the Gambian population, the largest number of schools per head (especially senior secondary schools), most of the industry and modern facilities such as tap water and electricity. Most of the country's tourism activity, embassies and international organisations are also concentrated here. The southern and eastern parts of these districts remain, however, predominantly rural, which is why we have used the term urban Kombo to refer to the conglomeration of towns and urban settlements in this part of the country.

Countrywide the rural areas are dominated by agricultural land which is predominantly used for growing groundnuts for export, and rice, fruit and vegetables for domestic consumption. In the rural area villages are made up of familial compounds. Traditionally men remain in the compound they are born into and women transfer to their husband's family compound on marriage. In this polygamous society each marriage unit and accompanying children occupy a house in the compound. The occupants of all the houses would be closely related and share chores, resources and child care. Familial compounds can also be found in the urban area, however, with a more transient population and more rented accommodation, the ethnic make-up of compounds can become complicated. Families renting a house, or houses, in an urban compound may find themselves sharing facilities with members of different ethnic and language groups, a situation that is rare in the rural areas.

\section{equinoxonline}


Despite its size, The Gambia is culturally, ethnically and linguistically diverse. As much information as possible about these concepts and how they interact has been included in the sections below. In section two an overview of the country's local languages and ethnicities is given, followed by a description of the role of English and Arabic and a discussion of the sociolinguistic situation regarding various groups of immigrants. In section three aspects of language use in different social domains are discussed.

\section{Languages and ethnicities in The Gambia}

\subsection{Indigenous languages}

In The Gambia, ten indigenous, 'local' languages are spoken. None are exclusive to The Gambia as each can also be found in Senegal and in other geographically close countries such as Guinea-Bissau, Guinea and Mali. A description of each of the languages follows an overview of the genetic classification (after Ethnologue 2005) depicted in Figure 2.

As can be seen in Figure 2, all Gambian languages fall under the family of Niger-Congo languages, but can be divided in two main branches of this phylum: Mande languages and Atlantic languages. Within the group of Mande languages, a central cluster of Manding languages can be discerned, including Mandinka, Bambara and Jahanka. These Manding languages are to a certain degree mutually intelligible and the people share a common history and culture (Sullivan 2004; Vydrine et al. 2000). This has led both locals and scholars to argue that Manding languages could be, or should be, regarded as a single language (cf. Prah 2003). Serahule is related to the Manding languages, but not closely enough to be included in the Manding group. Gambian languages in the Atlantic group all

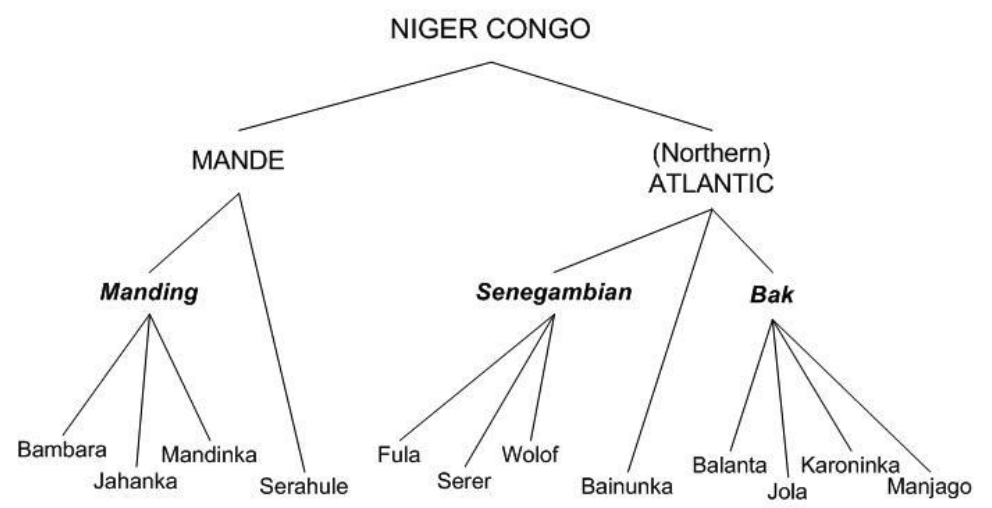

Figure 2: Genetic classification of Gambian languages

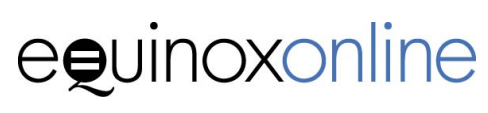


belong to the northern branch of this language family and can be subdivided into Senegambian (Wolof, Fula, Serer) and 'Bak' languages (Jola, Manjago, Balanta), plus Bainunka. The internal differences within the Senegambian and Bak groups are more substantial than those between languages of the Manding family. Not included in Figure 2 is Aku, an English-based creole language. While not strictly an indigenous language, it has been included in this section as a local language.

In government publications and policy documents five of the local languages are often cited as the main local languages. These five languages correspond with the five largest ethnic groups in The Gambia and are: Mandinka, Fula, Wolof, Jola and Serahule (usually cited in that order). In the decennial housing and population censuses that are organised by the Central Statistics Department (now Gambian Bureau of Statistics), there is a question on ethnicity but not on language use. Table 2 provides an overview of the share of the different ethnic groups in the Gambian population as counted in the censuses of 1973 to 2003. It is important to remark that even though each local language in The Gambia corresponds to an ethnic group, there is no one-to-one relation languageethnicity. While individuals belong to only one ethnic group, they often speak several languages, and not necessarily the language of their ethnic group.

Table 2: Gambian population by ethnicity $1973-2003$, in percentages ${ }^{3}$

\begin{tabular}{lrrrr}
\hline & $\mathbf{1 9 7 3}$ & $\mathbf{1 9 8 3}$ & $\mathbf{1 9 9 3}$ & $\mathbf{2 0 0 3}$ \\
\hline Mandinka & 42.3 & 40.8 & 39.5 & 35.9 \\
Fula & 18.2 & 19.0 & 18.8 & 21.9 \\
Wolof & 15.7 & 13.7 & 14.6 & 14.5 \\
Jola & 9.5 & 10.4 & 10.6 & 11.4 \\
Serahule & 8.7 & 8.3 & 8.9 & 8.2 \\
Serer & 2.1 & 2.5 & 2.8 & 3.1 \\
Manjago & 1.3 & 1.7 & 0.8 & 2.0 \\
Bambara & 0.4 & 0.5 & 0.7 & 1.1 \\
Creole (Aku) & 1.0 & 0.8 & 1.8 & 0.5 \\
\hline
\end{tabular}

\section{Mandinka}

Known as Sosseh in Wolof and as Cheddo in Fula, the Mandinkas are descendents of the Mali Empire that was founded by Sunjata Keita in the thirteenth century (Sonko-Godwin 2003:3; Faal 1997:7) and are almost exclusively Muslim $(99.8 \%){ }^{4}$ As the language of the largest ethnic group, Mandinka is the most widely spoken language in The Gambia, both as a first and second language, and carries some prestige because of its numerical majority and historical royal

\section{equinoxonline}


connections. In the majority of rural areas, as well as most of the towns located outside the Banjul and Kanifing LGAs, Mandinka functions as a lingua franca.

Mandinka is used in radio and in television broadcasting, although Wolof is increasingly being used in advertising and Kombo-based productions. Mandinka has an official, standardised orthography in Latin script with a strict phoneme-to-grapheme correlation, but as it is not taught in schools, written Mandinka does not usually adhere to the standardised version. Mandinka written with Arabic characters was taught in madrassa schools until fairly recently and still features on the official dalasi bank notes. ${ }^{5}$ It is not possible to confirm to what extent ajami, the practice of writing local languages with Arabic characters is still practiced. The N'ko alphabet, invented by Souleymane Kanté from Kankan in Guinea in 1949 (White Oyler 2001), has virtually no currency in The Gambia. Recent efforts by Guinean educators to introduce N'ko literacy did not succeed (Sidia Jatta, personal communication). Current organised efforts to promote and teach literacy in Mandinka use the Latin-based standard orthography. However, public written materials beyond learning materials and an occasional news bulletin, Kibaari kutoolu, are not readily available.

\section{Fula}

It has been stated that the Fula can be found 'in every modern West African state from Mauritania to Cameroon and the Republic of Sudan' (Sonko-Godwin 2003:42). The Senegalese Futa Toro and Guinean Futa Jalon highlands are believed to be the historical origin of all Fulas in West Africa. Fulas take pride in being among the first of all West African peoples to embrace Islam (Faal 1997:16) and today 99.7\% of Gambian Fula assert to be Muslim. ${ }^{4}$ Alternative names for the Fula people and language are Peul, Fulbe, Fulfulde, Fulani, Pulaar and Poular.

Many Gambian Fula are first or second generation migrants from Guinea, where Fula is a national language (see the growing numbers in Table 2). Originally nomadic cattle herders, rural Fulas are now cattle farmers and often rear the livestock of people from other ethnic groups for agreed benefits. Many Fula also run grocery shops and are sometimes involved in more substantial retail business, for instance the supply of textile and building materials. As rural tenants and urban traders in multi-ethnic environments, many Gambian Fula have gained fluency in the languages of their neighbours (Mandinka, Wolof, Jola, Serahule), thus removing the necessity for members of other ethnic groups to acquire high level second language proficiency in Fula. There are areas, however, especially in Fulladu, where Fulas form the majority and where Fula functions as a language of wider communication.

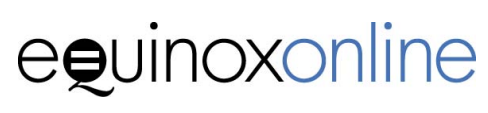




\section{Wolof}

Known as Surwa in Mandinka and Jolfeh in Fula, Wolof is the language of the third largest ethnic group in The Gambia, but is much more widely spoken as a second or additional language than Fula. The Wolof people, almost exclusively Muslim now, originate from the area north of the Senegal river, but migrated southward toward the Senegambian region when their homeland ran dry and established the states Jolof, Kayor, Walo and Baol and subjected the Serer states Sine and Saloum (Sonko-Godwin 2003; Faal 1997).

Wolof became the lingua franca of most of present-day Senegal and is becoming increasingly important in urban Gambia. In Banjul and the Kanifing Municipality, children of multiethnic parents increasingly grow up speaking Wolof as a first language and it is often also the preferred language of communication in ethnically mixed gatherings, for example school playgrounds and market places. This process of Wolofisation as described for Senegal (Mc Laughlin 1995; Ngom 2004) takes a similar shape in The Gambia. The Wolofisation of ethnic identities (Ngom 2004), however, may not be as pervasive in The Gambia as in Senegal, as it appears it is taking the form not of ethnic assimilation but of increased multilingualism, with Wolof becoming a more evident second or subsequent language.

Gambian Wolof should not be regarded as independent or unconnected to Senegalese Wolof, as it is recognised by speakers in The Gambia and Senegal, that despite lexical differences they are the same language. Although urban Gambian Wolof is characterised by extensive 'monolectal code-switching' (Meeuwis and Blommaert 1998) with English, French and Arabic, the level of hybridisation is reportedly not as advanced as in urban Senegal (cf. Swigart 1992; Haust 1995; Ngom 2004).

In addition to frequent use on television and radio, Wolof is also the language of mbalax music, which is immensely popular in The Gambia. This leads to the language having some prestige among the younger population. As with Mandinka, Wolof is also used in adult literacy classes but not in formal education. Wolof has an official, standardised orthography in Latin script, but is not widely distributed. At the same time, Wolof literacy in Arabic script continues to exist (on bank notes for instance), and is believed, by some of our informants, to be more widespread than literacy in Latin script.

\section{Jola}

Jola is classified as an Atlantic Niger-Congo language and is, according to Ethnologue (2005) rather a family of languages than a single uniform language. Little is known about the pre-colonial history of the Jola, but their origins

\section{ęuinoxonline}


are believed to be in the lower region of Casamance and parts of what is now Guinea-Bissau (Sonko-Godwin 2003:68). In The Gambia, Jolas are most populous in the Foni districts, the rural area east of Kombo. Although in Casamance there are substantial numbers of Christian and 'Animist' Jola, most Gambian Jolas are Muslim (91.6\%) with a notable minority of Christians (8.4\%). Large numbers of recent refugees and settlers from troubled Casamance have ensured this ethnic group has grown slightly in the past decade (see Table 2).

Jola is the ethnic group of President Yahya Jammeh, who has been head of state since 1994. Notwithstanding the recent increase in Jola speakers and the association with power through the president, the language has come under pressure in urban Kombo where, because of the mixed ethnicity of non-familial compounds, many Jola families are increasingly speaking Mandinka, Wolof or both. The domains in which Jola is used are minimal, therefore children of Jola families increasingly grow up speaking limited Jola, with Wolof or Mandinka as a first language. Although Jola is not listed in the UNESCO Red Book of Endangered Languages (Heine and Brenzinger n.d.), a decline in the functions and domains of Jola in The Gambia is undeniable.

Perhaps due to the constraints on the language the Jola are among the most multilingual people in The Gambia. Our Jola informants recognise this fact and confirm that they 'pick up' the languages of other ethnic groups if they live with them for a short time. They also lament the fact that majority language speakers can live with Jolas for years without understanding even the simplest and most common Jola phrases. In this context it is possible that language shift, language endangerment and ethnolinguistic vitality may have more to do with the attitudes of speakers of minority languages towards majority groups and their ability, interest, willingness and need to learn other languages rather than with 'linguistic imperialism' (Phillipson 1992) of any kind.

It is further worth noting that the ethnonym Jola was given to the Jolas by the Mandinka, in whose language joolaa means '(to) pay back'. The anecdotal etymology is that whatever (bad) Mandinkas did to Jolas, they paid them back with the same coin. Jola has overtaken the people's original name, Ajamataw, and is now used by all neighbouring ethnic groups.

\section{Serahule}

Serahule is a Mande language that developed from the proto-Mande branch before the Manding languages developed and dispersed into West Africa. The Serahule, also known by the French name Soninké, are the descendents of the Ghana Empire (ninth-thirteenth centuries) in what is now Central Mali, where they are still more populous than in Senegambia (Sonko-Godwin 2003; Faal 1997:18f). In The Gambia, they are concentrated in the eastern parts of the country, particularly around Basse, but also live in Kombo. Except for the

\section{equinoxonline}


area around Basse, members of other language groups generally do not speak Serahule. Gambian Serahule almost always speak Mandinka. Our observations suggest they are also increasingly speaking Wolof, particularly in urban Kombo. The Serahule, $99.9 \%$ of which are Muslim, ${ }^{4}$ are known to be international businesspeople trading in various commodities, including precious stones. A more recent enterprise is the building and renting out of apartment blocks in Greater Serrekunda and provincial towns.

\section{Serer}

The Serer, known as Kassinko in Mandinka, are a minority in The Gambia, but have a more significant population in Senegal. In The Gambia they are mostly found on the north bank and in Greater Serrekunda. The Serer are predominantly Muslim (97.3\%), while a small number of Serer families are Christian (2.7\%).

As has been reported for Senegal, the Serer are Wolofised to a great extent. The Serer who are culturally and linguistically related to the Wolof, have a precolonial history of both Wolof and Mandinka domination (Faal 1997:14). Today, many Serer, especially those whose mothers are of different ethnic groups, grow up speaking Wolof, and sometimes the mother's ethnic language instead of Serer. Indeed, our informants suggest that it would be 'virtually impossible' to find a Serer in The Gambia who does not also speak Wolof. As Ngom suggests, many Serer 'regard themselves as native Wolof speakers and lose their language and Seereer cultural identity' (2004:102). Few Gambians speak Serer as a second language. Of all the Gambian languages Serer is perhaps the one closest to being 'endangered' (Ngom 2004:103).

\section{Manjago}

The Manjago form one of the smaller ethnic groups in The Gambia and originate from what is now Guinea-Bissau. Manjago is the only ethnic group in The Gambia that is predominantly Christian (78.9\%) although significant numbers (20.8\%) have converted to Islam. ${ }^{4}$ They typically live on the south bank on the outskirts of villages that are 'owned' by Mandinkas and Jolas, or in urban Kombo. Very few persons of other ethnic groups speak even a limited amount of Manjago. Manjagos themselves however, like Jolas, are usually multilingual.

\section{Bambara}

Bambara is the branch of Manding people that are still living in the area in southern Mali bordering Guinea from where all Manding peoples originate. In Mali, Bambara is a national language and spoken as a lingua franca in and around the capital, Bamako. There is a small group of native Gambian

\section{equinoxonline}


Bambara, who are sometimes referred to in Mandinka as Tilibonkas, literally meaning 'those from the East'. Gambian Bambara migrated from the Manding area to what is now known as The Gambia long after Mandinkas inhabited the shores of the river Gambia, but long enough ago to become detached from the Bambara in Mali.

Mandinkas often claim that Bambara is 'deeper' than their own language, by which they mean more closely related to the ancient language of the Mali Empire, and that they cannot understand much of the language. Gambian Bambaras, and Bambara-speaking migrants from Mali, on the other hand, are culturally and linguistically integrated with the Mandinka and have no difficulties learning Mandinka. Like Mandinkas, Gambian Bambara are almost exclusively Muslim.

\section{Aku}

The Aku people settled in The Gambia around 1850. They are descendants of the Krio whose ancestors were former slaves in England and the Americas and recaptives from various parts of Africa brought together by the British in the province of freedom (Freetown) after the abolition of the slave trade (Faal 1997:20-23). Therefore, the Aku language, an English based Creole, is closely related to Sierra Leonean Krio. Members of the Aku ethnic group are most populous in the capital Banjul where they often own large colonial houses, witnessing the privileged position they had in the Bathurst-Freetown colonial administration. Aku is the only other ethnic group, after the Manjago, that is not predominantly Muslim: $51.1 \%$ are Christian while $48.8 \%$ are Muslims. ${ }^{4}$

It has been claimed in some sociolinguistic literature (Todd 1984:40-41; Crystal 2003:51; McArthur 2003:274) that Aku is used as a lingua franca in The Gambia. This was challenged by Peter and Wolf (2003:125) who argued that Aku is only used by a limited number of people in Banjul. Our findings confirm that today Mandinka and Wolof, not Aku, are used as linguae francae in The Gambia.

\section{Jahanka}

The Jahanka originate from Guinea and Mali and are traditionally Muslim. Like the Bambara, the Jahanka are an ethnic group that is closely connected to the Mandinka; so much that many Gambians will refute that the Jahanka are a separate ethnic group. However, many Gambian Jahanka defend that they are in the first place Jahanka and not Mandinka. Linguistically, the differences between Jahanka and Mandinka are limited to some lexical, tag, and inflection differences. Communication between Jahankas and Mandinkas is often completed using a parallel diglossic code rather than either interlocutor switching codes.

\section{equinoxonline}




\section{Karoninka}

The Karoninka originate from Casamance and have a similar ethnic origin to that of the Jola. Indeed, some claim they are the same people, however, with a similarity to the Jahanka-Mandinka relationship, the majority of Karoninka will declare they are a separate ethnic group despite the relatively mutually intelligible language. Due to their small numbers, marriage to members of other ethnic groups is common among the Karoninka and has been identified by the elders as one of the reasons for assimilation into both Islam and other language groups.

\section{Bainunka}

The Bainunka originate from Casamance in Senegal and Guinea-Bissau. Due to their low numbers verifiable information about this group is lacking.

\section{Balanta}

The Balanta are perhaps the smallest ethnic group in The Gambia and are concentrated in the Central River Region. Their origins lie in Guinea-Bissau where they form one of the major ethnic groups. In Guinea-Bissau, most Balantas are Christian, but in The Gambia many have reportedly adopted Islam. The Balanta language is most related to Jola and Manjago.

\subsection{Exogenous languages}

\section{English}

English is the official language in The Gambia and is widely spoken by young people, particularly in the urban areas. Generally speaking Gambians do not speak English with each other, unless in a specific domain. In urban Kombo, written English is highly visible, being used in street signs, on television and in newspapers. In the provinces access to written English is limited to the labels on food products and school text books. There are likely to be several people in each village able to communicate orally in English. However, the number of people with literacy levels sufficient to be able to undertake administrative tasks, such as letter writing and election duties, is usually limited to school teachers. As we discuss in section 3, the situations in which English is used depends on the participants involved in the activities as well as the purpose of the interaction.

Currently, British English is the standard in teaching materials, but Gambian English is the de facto standard in newspapers and other media output. There are significant differences between British English and Gambian English on

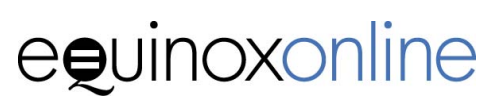


syntactic, lexical and phonological levels (Richmond 1989; Peter, Wolf and Simo Bobda 2003). As much as is clear from these initial accounts is that Gambian English is a variety in its own right within the (West) African branch of World Englishes. However, Gambian English does not exist in isolation from other varieties of English and is continuously exposed and influenced by other varieties of English in the world. A more comprehensive empirical study would be necessary to understand the complexities of Gambian English in relation to Aku, other varieties of West African English, British and other international Englishes.

\section{Arabic}

As a predominantly Islamic country, Arabic features considerably in The Gambia as part of religious practices. During traditional ceremonies which are conducted in indigenous languages frequent switches to Arabic occur for prayers and blessings. Arabic is not usually spoken between Gambians, however, formulaic phrases are mixed with all the local languages as well as English. The most common Arabic insertions are inshallah 'if God wills it', al-hamdulillahi 'thank God' and the exclamation Allahu akbar 'God is great'. For many, Arabic is also the default language for swearing, bilahi 'by God'. In addition to topic based code-mixes the use of Arabic features in the ritual greetings: in common with Muslims across the globe salaam aleikum 'peace be with you' and the response maleikum salaam 'peace also with you' is used as an initial greeting.

\subsection{Migrants and communication}

Its small size, political stability, the absence of serious crime and the relatively low cost of living, makes The Gambia an attractive place for citizens from the West African region and beyond. Table 3 shows the evolution of immigrants against the total population as measured in the last four censuses (GBoS 2007). Notwithstanding the official census counts, it is hard to obtain a reliable estimate on the total number of migrants, as the official numbers, 134,120 (12.9\%) for 1993, and 113,032 (8.3\%) for 2003, are believed to be considerable underestimations of the actual number of migrants in the country. It is highly unlikely that the share of migrants in relation to the general population has in actual fact declined between 1993 and 2003. ${ }^{6}$ The estimate of the World Bank of a stock of 231,739 immigrants in 2005, comprising $15.3 \%$ of the Gambian population, is therefore more plausible (Ratha and Xu 2006).

As an enclave in the vast area of what used to be l'Afrique Occidentale Française, The Gambia receives most of its immigrants (80\%) from countries where

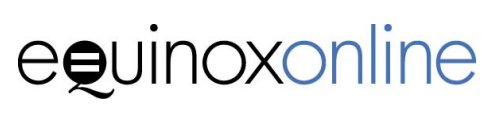


Table 3: Immigrants in The Gambia 1973-2003 (GBoS 2007)

\begin{tabular}{lllll}
\hline & $\mathbf{1 9 7 3}$ & $\mathbf{1 9 8 3}$ & $\mathbf{1 9 9 3}$ & $\mathbf{2 0 0 3}$ \\
\hline total population & 493,499 & 687,817 & $1,038,145$ & $1,360,680$ \\
Senegalese & 25,309 & 32,385 & 81,567 & 61,862 \\
Guinea (Conakry) & 10,137 & 12,599 & 27,797 & 23,386 \\
Guinea-Bissau & 6,817 & 5,626 & 8,488 & 5,516 \\
Mali & 5,467 & 4,295 & 6,370 & 3,329 \\
Mauritania & 1,883 & 1,828 & 2,243 & 2,446 \\
Sierra Leone & 436 & 517 & 1,607 & 7,568 \\
Nigeria & - & - & - & 2,864 \\
Ghana & - & - & - & 1,487 \\
Liberia & - & - & - & 310 \\
Other W-Africans & - & - & - & 228 \\
Other Africans & 794 & 1,023 & 2,564 & 375 \\
Non-Africans & 1,159 & 2,523 & 3,484 & 3,661 \\
total immigrants & 52,002 & 60,796 & 134,120 & 113,032 \\
\% of population & $\mathbf{1 0 . 5 \%}$ & $\mathbf{8 . 8 \%}$ & $\mathbf{1 2 . 9 \%}$ & $\mathbf{8 . 3 \%}$ \\
\hline
\end{tabular}

French remains the official language. The majority of 'Francophone' migrants come from Senegal, both from northern Senegal and the southern Casamance region, where a longstanding, at times violent, conflict has caused many to flee their homeland. Culturally, historically and linguistically, Senegal and The Gambia form a unity that is hardly interrupted by the national boundaries. Senegalese nationals experience no communication difficulties in their daily dealings with Gambians and gain easy access to the job market as most trades function in a predominantly oral and informal economy. A significant number of migrants also come from Guinea and Mali, countries at approximately two to three-day overland journey distance. Guinean migrants are mainly Fulas and Mandinkas and often work as grocery shopkeepers or as taxi drivers in urban Kombo, while Malians, often Bambaras, are employed in various sectors.

The Gambia also receives a significant number of Anglophone West African migrants (11\%). In contrary to the 'Francophones' who have also settled in the rural areas, the Anglophones are predominantly urban based. The two largest groups in this category, Sierra Leoneans and Nigerians, represent two different motives for migration. Nigerians are usually travellers by choice (economic migrants) while Sierra Leoneans, until very recently were travellers by force (political refugees). Nigerians, like Ghanaians, have generally come to The Gambia to establish a business or to work in education. Many Sierra Leoneans, on the other hand, came to The Gambia to flee the civil war of the 1990s and many have taken up jobs in the public and private education sector. Sierra 
Leoneans, generally referred to by Gambians as Freetownians whether or not they are from the capital Freetown, are mainly speakers of Krio, the national lingua franca, but also of languages including Mende and Temne. Discussions with Gambian-based Nigerians reveal that Nigerians involved in business are often of the Igbo ethnic group, while those working in the secondary and tertiary education sector are typically Yoruba. It has been noted that few male Anglophone West African migrants, even those who have married Gambians, have found it necessary to learn any of the indigenous Gambian languages beyond basic communication.

The problem with the terms 'Francophone' and 'Anglophone' as used in this context, is that Francophone here has a rather different meaning than Anglophone. 'Francophone' West Africans in The Gambia may be from countries colonised by the French but this does not guarantee their ability to communicate in French. In their daily lives, their Francophoneness is less useful to them than their respective ethnic identities and local language competencies. For the Anglophone migrants, however, it is precisely their Anglophoneness that they share with Gambians. Therefore English, or a creolised variety of it in the case of Sierra Leonean Krio and Nigerian Pidgin English, is widely used in their daily routines.

Also from West Africa are migrants from Guinea-Bissau, where the official language is Portuguese. For them the same theory as for the Francophone migrants can be applied, as their national lingua franca, Portuguese-based Crioulo, does not hold currency in The Gambia. Instead, in order to communicate they must rely on mutually intelligible ethnic languages, or their ability to learn a Gambian language. In fact, migrants from Guinea-Bissau are often of ethnic groups that already occupy The Gambia, particularly Mandinka and Fula.

A fourth category of migrants are Arabophones, including Mauretanians from the sub-region and Lebanese from the Middle East. Mauretanians are sometimes Wolofs from the area north of the river Senegal, but mostly of Arabic or Berber descent. Most of them speak Hassaniya Arabic as a first language and French as a second language; some also speak Wolof. Mauretanians based in The Gambia for an extended period of time, typically running provisions shops or shawarma restaurants, will usually learn the vehicular language of the community in which they settle. The Lebanese are speakers of (Lebanese) Arabic and are a small but significant immigrant group that are often involved in substantial business and trade. As an illustration, two of the three mobile telephone providers in The Gambia are owned by Lebanese (cf. Leichtman 2005).

Two relatively new categories of immigrants to The Gambia, both of which rely on English in their communication with Gambians, are Indians and

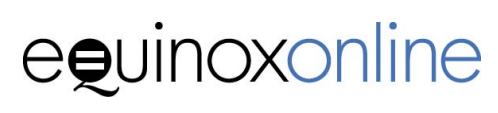


Chinese. Individuals from both the People's Republic and Taiwan are often involved in retail businesses selling clothes, shoes and other materials that are made in China, and in other sectors as well. Diplomatically, The Gambia maintains relations only with the Taiwanese government, who are an important foreign aid donor (Baker and Edmonds 2004). Similarly, Indians are involved in the business of selling goods imported from India, focusing on household electronics and building materials. Although increasingly more visible in The Gambia, reliable information on the economic and sociolinguistic circumstances of Indian and Chinese immigrants remains open for further investigation.

Other temporary migrants, or long stay visitors, are American Peace Corps volunteers (PCVs), British Voluntary Service Overseas volunteers (VSOs) and Cuban doctors. There are approximately 100 PCVs in The Gambia at any time, while there were $31 \mathrm{VSO}$ in 2007. Both receive language training and spend long uninterrupted periods in communities where English is not used outside the classroom and therefore become fluent in the local language of the community they are resident in (VSO 2007; Peace Corps 2007). Cubans generally do not achieve functional proficiency in Gambian local languages (see section 3.7).

\section{Language use in social domains}

\subsection{Education}

The education system in The Gambia is organised in a 6-3-3 structure, consisting of six years of lower basic school and three years of upper basic school, forming a nine year basic education cycle, followed by three years of senior secondary schooling. Nursery schooling is necessary as a preparation for lower basic school, but is not provided by the government, confining it to the private sector. Section 30(a) of the Gambian constitution stipulates that 'basic education shall be free, compulsory and available to all' (RoTG 2002), but in practice school attendance is not enforced.

The Gambia currently operates an English-only language policy in all levels of education, with the exception of Qur'anic schools. As discussed above, the standard of written materials is British English which is also the expected standard for examinations. There have been moves to introduce some of the major indigenous languages as media of instruction for early years education (DoSE 2004:35). However, at present, materials and associated teacher training have not been developed and the implementation is not anticipated in the near future. 
Teachers are among the most multilingual persons in Gambian society, having opportunities to develop their language repertoires when they are posted to communities with different sociolinguistic profiles. In contrary to the English-only policy, switches to local languages are common within Gambian classrooms. It is local languages that are usually used in the nonteaching areas of schools: pastoral care and playground activities. Which local language appears to depend on several factors, including the most dominant local language and the proficiency of teacher and child in a particular language. On several occasions switches to minority languages have been witnessed to assist a distressed or sick child, with teachers calling on other children to step in as translators where necessary. In the playground children appear to have an innate understanding of which language to use (see McGlynn and Martin 2009; McGlynn forthcoming).

Children in Gambian schools have regular religious education lessons which are conducted in Arabic. During these lessons children receive instruction in the Qur'an, the daily prayers, washing and other rituals. Christian children are usually withdrawn from these lessons and, if appropriate, alternative religious classes are organised in English.

Parallel to the public education system are two types of Islamic schooling: daara are informal classes, organised by men who are versed in the Qur'an (often imams), where children are taught to recite and write the suras of the Qur'an; madrassa is the Arabic alternative to English-based schooling and offers a full curriculum although the majority of time is spent on Islamic tuition. Our research indicates there have been no empirical studies of the language used in either type of Islamic education in The Gambia. Our informants advise that the language used in the classroom is a mixture of Arabic, local languages, and some English depending on the level of the students. A madrassa teacher advised that from nursery to grade four the local language of the community is used, in grades five and six Arabic is used as the language of instruction, with support from the local languages as often as the children need it, and from grades seven to twelve only Arabic is supposed to be used with English reserved for English lessons.

\subsection{Religion}

As can be seen from Table 4, there are, in practice, only two religions in The Gambia, Islam and Christianity. Muslims make up about $95 \%$ of the Gambian population and despite their numerical dominance respect the religious otherness of the Christian minority which amounts to 3 or $4 \%$. Contrary to 
descriptions in travel guides of Gambian culture, adherence to traditional religions is, percentagewise, negligible.

In his book Translating the Message (1989), the Gambian American scholar Sanneh contrasts the Islamic stance regarding the untranslatability of God's word with Christianity's emphasis on translation to transmit God's word. This is evident during the Friday prayers, when the imam preaches in Classic Arabic followed by an explanation in the most widely understood local language of the community. At other times of the week Muslims say personal prayers on a mat at home, at work or in a mosque in Classic Arabic. Christians pray in English and/or their respective local language. All denominations of Christian service on Sunday are organised in a mixture of local languages and English. Unlike the post-Arabic explanation of the lesson in the mosque, the sermon or homily in Christian churches is given in English with a concurrent translation into a local language. Newborn congregations in urban Kombo receive many Nigerian and Sierra Leonean worshippers and are organised in English only. Christian radio and television programmes are also in English while Islamic broadcasts are in Arabic with accompanying clarifications in English and/or one or more local languages.

Table 4: Religion in relation to ethnicity and nationality, in percentages ${ }^{7}$

\begin{tabular}{lccc}
\hline & Islam & Christianity & Traditional \\
\hline Mandinka & 99.8 & 0.2 & 0.02 \\
Fula & 99.7 & 0.3 & 0.01 \\
Wolof & 99.7 & 0.3 & 0.01 \\
Jola & 91.6 & 8.4 & 0.06 \\
Serahule & 99.9 & 0.1 & - \\
Serer & 97.3 & 2.7 & - \\
Manjago & 20.8 & 78.9 & 0.22 \\
Bambara & 99.2 & 0.8 & - \\
Creole/Aku & 48.8 & 51.1 & - \\
Other Gambians & 75.7 & 24.2 & - \\
total Gambians & $\mathbf{9 6 . 6}$ & $\mathbf{3 . 4}$ & $\mathbf{0 . 0 2}$ \\
Francophone West African migrants & 96.0 & 3.9 & 0.03 \\
Anglophone West African migrants & 38.5 & 61.1 & 0.07 \\
migrants from Guinea-Bissau & 55.5 & 43.5 & 0.65 \\
other African migrants & 72.6 & 25.7 & 0.50 \\
non-African migrants & 28.8 & 55.9 & 0.44 \\
total population of The Gambia & $\mathbf{9 5 . 4}$ & $\mathbf{4 . 3}$ & $\mathbf{0 . 0 3}$ \\
\hline
\end{tabular}




\subsection{Politics and law}

We are unaware of any studies into the use of language in the political and legal arena, however, in common with many post-colonial countries where governance is conducted in the language of the former colonial occupier, The Gambia uses English in all its national political dealings. Section 105 of the Gambian constitution provides that 'the business of the National Assembly shall be conducted in the English language or any other language prescribed by an Act of the National Assembly' (RoTG 2002:\$105). Informants involved in the political community have advised that meetings, even minor committee meetings, are always held in English and all documentation is only produced in English. Informal discussions, greetings and general talk is conducted in local languages, however if the topic of the conversation becomes official in any way, the interlocutors switch to English. Local level political rallies (bantaba), often held during election campaigns by all political parties, generally use the lingua(e) franca(e) of the local community.

Concerning law enforcement, the Gambian constitution contains a provision that "[e]very person who is charged with a criminal offence - (b) shall be informed at the time he or she is charged, in a language which he or she understands and in detail, of the nature of the offence charged' and '(f) shall be permitted to have without payment the assistance of an interpreter if he or she cannot understand the language used at the trial of the charge' (RoTG 2002:\$24(3)). One of our informants advises that police officers generally speak Mandinka and Wolof in addition to their ethnic group language. Court judges, who are often Nigerian nationals, speak English, relying on translation into whatever the defendants claim to be their first language. It would appear therefore that the use of local languages with local people is to facilitate the legal process with full understanding on all sides.

\subsection{Media}

Television in The Gambia has become more popular with the electrification of many areas and the availability of equipment, and is no longer the sole pleasure of the (urban) elite. The daily news bulletins are in English, Mandinka, Wolof and Fula, with 'minority languages' Jola and Serahule, used on alternate days. Television is targeted for an urban audience and therefore the majority of programmes and advertisements make use of Wolof and/or English.

There are several radio channels in The Gambia. On urban based stations, including Radio Gambia and West Coast Radio, English and most of the local languages can be heard everyday. Community stations, for example Radio Basse, are dominated by local languages. Many programmes offer the opportunity for listeners to call in and voice opinions on current issues or specific

\section{equinoxonline}


debates. Here, the ethnolinguistic diversity is reflected in multilingual radio broadcasting with English, Wolof, Mandinka and other local languages cooccurring in a single programme.

Despite critique on Gambia's human rights record with regard to freedom of speech (N'Diaye et al. 2005), there are several newspapers produced either daily or two to three times weekly: The Daily Observer is a privately owned pro-government newspaper, The Point is opposition minded, as is Foroyaal Freedom, which is edited by one of the main opposition parties. Although they are all referred to as national papers, the editorial offices are exclusively based in urban Kombo and their organised distribution is limited to the urban west. Newspapers feature news that is first and foremost made in the Kombos with occasional stories about the provinces. All newspapers are written in Gambian English, or Gamblish as one informant called it. In this respect, Bojang (2004) has humorously written stylistic advice to Gambian journalists. Some newspapers feature occasional news in French and local languages, or have a religious column in Arabic on specific days of the week. There are news bulletins available in Mandinka, Wolof, Fula and Jola, that are produced by voluntary organisations such as WEC International, however they are not widely circulated and do not follow a strict distribution time-scale.

\subsection{Traditional and popular culture}

Traditional celebrations are still very much a part of rural Gambian life and also feature in urban areas. Marriages and naming ceremonies are common in both areas, but circumcision rituals, both for boys and girls, tend to be rural activities with many family members returning to their home village for these occasions. Traditional weddings and naming ceremonies are undertaken in the local language of the participants but have several phases, particularly blessings and prayers, that are conducted in Arabic. Although entry to circumcision rituals is impossible for an outsider (Hudson 1990), information from candidates tell us that only local languages are used. The Mandinka character of Kangkurang, a full length mask that deters evil spirits and actually conducts the circumcision of boys, does not speak at all, but its behaviour is interpreted into local language by initiated members of the community. Kangkurang performances, as well as the masquerades of other ethnic groups, the Wolof Zimba, Jola Mamapara and Kumpo and Aku Agugu, bear deep historical-cultural meanings, however, they are also staged for urban and multiethnic audiences for the sake of art itself and increasingly to raise money (Weil and Saho 2005).

Popular music in The Gambia varies from African, (African) American and Caribbean music genres. Of the African styles, Wolof mbalax (literally meaning 'music') and Afro-Manding are most popular. Both have their origins in griotism. Several popular Senegalese mbalax artists, including Youssou

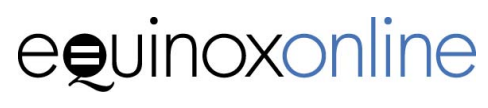


N'Dour, Baaba Maal and Vivian, regularly perform in The Gambia. The most popular Afro-Manding group, singing in Mandinka, is the Gambian group Jaliba Kuyateh and the Kumareh band. Malian music with lyrics in Bambara (an example is Oumou Sangaré), is also admired. Of the non-African music styles reggae, hiphop and R\&B are most often heard. Apart from reggae legends Bob Marley and Burning Spear, Siddy Rank and Anthony B. are immensely popular in The Gambia, owing to regular visits with live performances. Local reggae musician Njie B, as well as R\&B/hiphop artists Sing'a'teh (Freaky Joe) and Nancy Nanz, enjoy celebrity status in The Gambia, singing primarily in English.

Urban Gambians watch a variety of films produced by the three major centres of film production in the world: Hollywood (America), Bollywood (India) and Nollywood (Nigeria). Of these three, Nigerian films are preferred by many young Gambians over American films, because of their greater adherence to realism and the choice of its themes (cf. Omoniyi 2008). Indian films are becoming increasingly popular in The Gambia evidenced by the increasing number of titles in rental stores.

\subsection{Tourism}

There is a growing number of tourists who visit The Gambia. In 2006, the number of tourists exceeded 121,000 which meant a 9.5\% increase on the previous year. The tourism high season falls from November to April and coincides with the dry and cooler months of the year. Despite continuous attempts by the Gambian government to promote all year round tourism (Thompson et al. 1995:579), for most tourists The Gambia is still a 'winter sun' destination, thus avoiding the Gambian rainy season (June to September).

A first category of tourists is 'sun and sand seekers' from the United Kingdom (53\%), the Netherlands (15\%), Scandinavia (10\%), Germany (5\%), Finland (3\%), and, more recently, Spain (3\%), (GTA 2007). ${ }^{8}$ Although a large number of these tourists are one-off visitors, many are also returning visitors. Some of the returning visitors become involved with The Gambia in a way that goes beyond the usual activities of tourism: some become romantically involved with Gambians (Nyanzi et al. 2005) while others privately initiate small-scale development projects (Juffermans 2008b).

A smaller, second category of tourists are Americans and Canadians, who account for $2 \%$ of Gambian tourism with an average 2,200 visitors annually. Many are African-Americans following in the footsteps of Alex Haley in search for their Roots, the title of Haley's (1977) book in which he traces his ancestry through the trajectories of slavery back to the village of Juffureh in Upper Niumi District (cf. Ebron 2002; Wright 1981).

\section{equinoxonline}


Both Europeans and North Americans communicate primarily in English with Gambians, and although there are inevitable communication difficulties due to the differences between American, British, the various mainland European Englishes and Gambian English, gross communication breakdowns are rare. Both Gambians working in the industry as well as most tourists, including those from non-Anglophone countries, usually speak enough English to manage service encounters and engage in more meaningful conversations (cf. Lawson and Jaworski 2007). In addition, a number of Gambians working in the tourist industry have obtained knowledge of many European languages to be able to greet or offer more extensive services to tourists in their own language.

\subsection{Health care}

To our knowledge there has been no empirical research about the use of language in the health sector. The Gambia relies heavily on foreign doctors and senior medical personnel, especially from Nigeria and Cuba, which often results in communication difficulties. It is understood that visiting doctors rarely learn any of the local languages. The Cuban doctors, employed by The Jammeh Foundation on temporary contracts, ${ }^{9}$ tend to speak Spanish and varying degrees of English, whereas Nigerian doctors are generally fluent in English. Many of their patients, especially rural women and their children, do not generally speak English. As a result, doctors and patients manage with limited English, ad hoc sign language and the assistance of other patients acting as translators. It has been noticed that in order to reduce confusion medicines are frequently distributed with pen strikes on the labels to indicate how often it should be administered.

In healthcare facilities in urban Kombo, including the Royal Victoria Teaching Hospital in Banjul, Wolof is the lingua franca, whereas Mandinka is used in the majority of areas outside the Kombos including the second largest hospital at Bansang. Both Fula and Mandinka are used in the major health care facility in Basse.

\subsection{Public transport, markets and streets}

Public transport, which in actuality is privately owned transport organised for the public, is a sector that thrives with a lingua franca. In urban Kombo this is Wolof. When taking transport from the Kombos to the provinces on the south bank, it is usual to change vehicles at Brikama garage, a major hub for travellers. From Brikama to the rural areas Mandinka is spoken in the vehicles. When travelling to eastern towns on the north bank it is more usual to cross the

\section{equinoxonline}


river using the Banjul to Barra ferry. Wolof is the vehicular language along this route. However, from Farrafenni, a town some 80 kilometres beyond Banjul, the language of the communities is predominantly Mandinka and therefore vehicle drivers are usually able to communicate in both languages.

Markets are eclectic places where everything from food to batteries to clothes to building materials can be bought. Wolof appears to be the dominant language in the urban area, even though Mandinka is still used by many of the older generation. One informant expressed very strongly how he refuses to speak Wolof in the market place, even though he can speak it perfectly adequately, as he dislikes the way the younger people have adopted Wolof so readily. In the rural weekly markets (lumoo), the respective lingua franca of the area is used.

In the streets, one notices the functional dichotomy of spoken and written language: whereas local languages can be heard ubiquitously, it is only English, and Arabic to a lesser extent, that can be seen on shop signboards and other public inscriptions in the linguistic landscape (Juffermans 2008a). The emergence of Wolof slogans in visual advertising such as mobile telephone provider Gamcel's Yaay Borom (literally meaning 'it's yours'), may signal a change to this situation.

\section{Concluding remarks}

As can be seen from above, the indigenous languages of The Gambia are diverse in their origin and uses. The Gambia's two most widely spoken languages, Mandinka and Wolof are typologically quite different and fall under two distinct language families, Mande and Atlantic languages respectively. The lingua franca in The Gambia is not Aku or an English-based Creole, as can sometimes be read in the literature, but Wolof and Mandinka instead. Our informants concur that it is hard to find a Gambian person of any age or ethnic group that speaks neither Mandinka nor Wolof.

With regard to the social uses of language it is surprising to register that the languages are domain dependent, as is the case of law and education; geographically determined, with regard to public transport and religion; and age related, as identified by several informants about their personal language use. This ethnic and linguistic diversity does not, however, lead to any noticeable friction between people. Instead, the acceptance of other languages can lead to viable multilingualism and extended code-switching between languages in order to facilitate communication by all parties involved in a conversation. This synergy of languages is particularly important as it could be said that talking is one of the national pastimes. As each culture has its own stereotypical social meeting place, Gambians have their social gatherings on street corners or under the shade of a mango tree. Groups of men meet to brew attaya, the

\section{equinoxonline}


strong, sweet, Chinese green tea, and during the process which takes several hours, social talking takes place. All mature men are welcome to join the discussion which means that often several languages can be heard during the conversation. This specific situation, along with the other areas discussed in section three, illustrates the linguistic creativity of Gambian nationals to accommodate multiple languages.

That said, recognition must be given to the increasingly obvious use of Wolof in urban Kombo. The frequency with which this language is now heard in several of the domains in which minority languages were used until recently, appears to have increased drastically. Minority languages Serer and Jola appear to have lost the most in terms of domain usage, indeed many younger generation Serers and Jolas can no longer justifiably claim their ethnic language as their first language. The realisation that even majority language speakers, the Mandinka, are increasingly learning Wolof to ensure they are able to communicate effectively with all Gambians is an indication that Wolof is encompassing more domains.

The various influences on the languages make the linguistic situation both dynamic and ripe for further research. Indeed, this paper suggests there are several linguistic phenomena and numerous sociolinguistic domains that have not been studied thoroughly. It is clear that far more research is necessary to begin to understand the complexity of language use in The Gambia.

\section{Acknowledgements}

We wish to thank the guest editor of this special issue for allowing us to present a general overview of the language situation in The Gambia, which we find important given the scarcity of reliable and up-to-date information on the sociolinguistics of this small country. Although the theme of language shift is not explicitly addressed throughout the paper, we do believe that this detailed description of the dynamic sociolinguistic profile of one country contributes to an understanding of changing ecologies of language in West Africa. With gratitude we recognise the wealth of local information provided by our friends and colleagues in The Gambia. In particular we acknowledge the input of the following colleagues, without whom this paper could not have been produced: Kemo Bah, Mustapha Barry, FaMalang Bojang, Sheriff Bojang, Babucar Cham, Essa Coker, Musa Colley, Inspector Jammeh Ceesay, Almameh Janneh, Malanding S. Jaiteh, Sidia Jatta, Alhagie Kanyi, Mariatou Sainey Kanyi, Alieu Sarr, Lamin Sonko, and Salieu Touray. We are also grateful to Sjaak Kroon and two anonymous reviewers for careful readings of the text and insightful suggestions. Caroline McGlynn would like to take this opportunity to express her profound gratitude and respect to the late Professor Peter Martin.

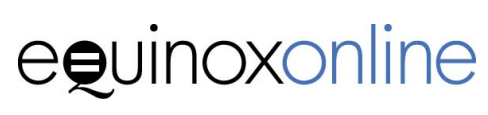




\section{About the authors}

Kasper Juffermans is an Africanist and sociolinguist at the Department of Language and Culture Studies and a member of the Babylon Centre at Tilburg University. Since 2004, he has conducted an aggregate twelve months of fieldwork in both urban and rural Gambia, studying the linguistic landscape, language in education, the social context of (il)literacy and spelling practices in Mandinka. Kasper is in the final stages of completing his $\mathrm{PhD}$ on literacy products and practices in Gambian society.

Caroline McGlynn is a lecturer in linguistics in the Cass School of Education at the University of East London and a member of the BAAL Language in Africa Special Interest Group. Her particular interests include code-switching, the projection of identity through language use and traditional talk in contemporary societies. Caroline has had an academic interest in The Gambia since 2002 and is currently writing up her Doctoral research which investigates the use of local languages in education.

\section{Notes}

1 It is usual to write 'The Gambia' with the definite article and a capital 'T'. We have followed this convention throughout this paper. According to Abdoulaye Saine (2006), the use of the definite article indicates that The Gambia was a possession of Britain and distinguishes it from the southern African state Zambia. Hassoum Ceesay (2005), writes that 'Gambia refers to the river; the Gambia refers to the old colony replaced since 18 February 1965 with a new independent country called The Gambia. The capital letter $\mathrm{T}$ in the must be maintained because it also signifies our dignity and pride as a sovereign nation. The official name of our country is The Gambia and laziness, sloppiness or sheer ignorance should not make anyone write it as Gambia or the Gambia, which is in fact, colonial and reminds us of the lame 120 years spent under colonial rule'.

2 It is not clear if the Banjul and Kanifing LGAs fall under Western Region or not.

3 Mandinka includes Jahanka; Fula includes Tukulor and Lorobo; Jola includes Karoninka.

4 All cited percentages on religion and ethnicity are from the 2003 Housing and Population census and were obtained through personal communication (GBoS 2007). The figures are summarised in Table 3.

5 Dalasi bank notes contain the denomination in English (e.g., TEN DALASIS) and under that, from right to left the denomination in Mandinka (اذ نسلد) 'dalasi tan') and Wolof (نسلد كـف 'fuki dalasi') in Arabic script.

\section{equinoxonline}


6 It was admitted at the GBoS (2007) that, in spite of principles of anonymity, many migrants may have said to be Gambian for fear of becoming traceable by the immigration authorities and having to pay the annual alien tax. Aliens who can most successfully claim Gambian identities are migrants from Senegal, the two Guineas and Mali, because their ethnolinguistic identities are compatible with Gambian ethnicities. Note that the number of 'Anglophone' migrants in the Census figures increased with a factor of 2.9 between 1993 and 2003 compared to a general population growth of $31 \%$.

7 The 2003 census also identified a fourth category of 'other religion', which yielded, except in the category of non-Africans, even smaller numbers than in the column of traditional religion (GBoS 2007). Regarding labels of ethnicity, the same applies as in Table 2: Mandinka includes Jahanka; Fula includes Tukulor and Lorobo; Jola includes Karoninka. Francophone migrants are Senegalese, Guineans, Malians and here also Mauritians; Anglophone West Africans are from Sierra Leone, Nigeria, Ghana and Liberia.

8 The total number from which percentages are drawn excludes Gambian nationals (6\%) visiting their country while residing abroad or returning home by air after overseas travelling.

9 The Jammeh Foundation is a national charitable organisation presided over by the current president of The Gambia and the first lady. In addition to $\mathrm{Cu}$ ban doctors the Jammeh Foundation also funds school places for girls and provides scholarships and other training opportunities.

\section{References}

Baker, K. M. and Edmonds, R. L. (2004) Transfer of Taiwanese ideas and technology to The Gambia, West Africa: A viable approach to rural development? The Geographical Journal 170(3): 189-211.

Bojang, S. (2004) Handbook for Journalists. Bakau: Observer Press.

Ceesay, H. (2005) Gambia, The Gambia, the Gambia. Daily Observer. 14 November 2005.

Crystal, D. (2003) English as a Global Language. Cambridge: Cambridge University Press.

DoSE (2004) Education Policy 2004-2015. Banjul: Department of State for Education.

Ebron, P. A. (2002) Performing Africa. New Haven: Princeton University Press.

Ethnologue (2005) Ethnologue: Languages of the World. (15 th edition.) R. G. Gordon, Jr. (ed.) Dallas: SIL International. (Online edition:www.ethnologue.com)

Faal, D. (1997) A History of The Gambia: AD 1000-1965. Latrikunda: Print Promotion.

GBoS (2007) Population and Housing Census 2003. Personal communication with Mr Alieu Sarr: Specific enquiries into ethnicity, literacy, migration, religion. Kanifing: Gambian Bureau of Statistics. 
GTA (2007) Monthly Tourists Arrival by Nationality, January 2004-September 2007. Personal communication with Mr Essa Coker. Kololi: Gambia Tourism Authority.

Haley, A. (1977) Roots, The Saga of an American Family. London: Hutchinson.

Haust, D. (1995) Codeswitching in Gambia. Eine soziolinguistische Untersuchung von Mandinka, Wolof und English in Kontakt. Cologne: Rüdiger Köppe.

Heine, B. and Brenzinger, M. (n.d.) Endangered languages in Africa. In UNESCO Red Book of Endangered Languages. Tokyo: UNESCO.

Hudson, M. (1990) Our Grandmothers' Drums: A portrait of rural African life and culture. New York: Grove Weidenfeld.

Jaiteh, M. S. and Saho, A. (2006) The Atlas of 2003 Gambia Population and Housing Census. Banjul: Gambia Bureau of Statistics.

Juffermans, K. (2008a) Local emplacement and global identities in signboard and billboard literacies in urban Gambia. In A. Simo Bobda (ed.) Explorations into Language Use in Africa 197-219. Frankfurt: Peter Lang.

Juffermans, K. (2008b) The discourse of lending aid on small-scale development project websites: Dutch depreciatory diminutives. Language Matters 93(1): 126-145.

Lawson, S. and Jaworski, A. (2007) Shopping and chatting: Reports of tourist-host interaction in The Gambia. Multilingua 26: 67-93.

Leichtman, M. A. (2005) The legacy of transnational lives: Beyond the first generation of Lebanese in Senegal. Ethnic and Racial Studies 28(4): 663-686.

McArthur, T. (2003) Oxford Guide to World English. Oxford: Oxford University Press.

McGlynn, C. (forthcoming) An Investigation into Classroom Language in Multilingual Areas of The Gambia. PhD Dissertation, University of East London.

McGlynn, C. and Martin, P. (2009) 'No vernacular': Tensions in language choice in a sexual health lesson in The Gambia. International Journal of Bilingual Education and Bilingualism 12(2): 137-155.

Mc Laughlin, F. (1995) Haalpulaar identity as a response to Wolofization. African Languages and Cultures 8(2): 153-168.

Meeuwis, M. and Blommaert, J. (1998) A monolectal view of code-switching: Layered code-switching among Zairians in Belgium. In P. Auer (ed.) Code-switching in Conversation: Language, interaction and identity 76-98. London: Routledge.

N'Diaye, B., Saine, A. and Houngnikpo, M. (2005) Not Yet Democracy: West Africa's slow farewell to authoritarianism. Durham: Caroline Academic Press.

Ngom, F. (2004) Ethnic identity and linguistic hybridization in Senegal. International Journal of the Sociology of Language 170: 95-111.

Nyanzi, S., Rosenbergh-Jallow, O., Bah, O. and Nyanzi, S. (2005) Bumsters, big black organs and old white gold: Embodied racial myths in sexual relationships of Gambian beach boys. Culture, Health and Sexuality 7(6): 557-569.

Omoniyi, T. (2008) Nollywood and the continentalization of Nigerian English. Presentation at Sociolinguistics Symposium 17. Amsterdam, 4 April.

Peace Corps (2007) Personal communication with PCV Binta Yaffa.

\section{equinoxonline}


Peter, L. and Wolf, H.-G. (2003) Aku in The Gambia: Terminological problems, functional distribution and popular attitude. In P. Lucko, L. Peter and H.-G. Wolf (eds) Studies in African Varieties of English 119-127. Bern: Peter Lang.

Peter, L., Wolf, H.-G. and Simo Bobda, A. (2003) An account of distinctive phonetic and lexical features of Gambian English. English World-Wide 24(1): 43-61.

Phillipson, R. (1992) Linguistic Imperialism. Oxford: Oxford University Press.

Prah, K. K. (2003) Going native: Language of instruction for education, development and African emancipation. In B. Brock-Utne, Z. Desai and M. Qorro (eds) Language of Instruction in Tanzania and South Africa 14-34. Dar-es-Salaam: E\&D.

Ratha, D. and Xu, Z. (2006) Gambia, The. In Migration and Remittances Factbook. Washington, DC: World Bank.

Richmond, E. B. (1989) African English expressions in The Gambia. World Englishes 8: 223-228.

RoTG (2002) Constitution of the Republic of The Gambia, 1997 (with 2001 amendments). Banjul: Republic of The Gambia.

Saine, A. (2006) Underreported: Politics in The Gambia. Interview, The Leonard Lopate Show, New York: WNYC Radio. 28 September 2006. Available online.

Sanneh, L. (1989) Translating the Message: The missionary impact on culture. Maryknoll: Orbis.

Sonko-Godwin, P. (2003) Ethnic Groups of the Senegambia. A Brief History. Banjul: Sunrise.

Sullivan, T. D. (2004) [1983] A preliminary report of existing information on the Manding languages of West Africa: Summary and suggestions for future research. SIL Electronic Survey Report. Dallas: SIL International.

Swigart, L. (1992) Two codes or one? The insiders' view and the description of codeswitching in Dakar. Journal of Multilingual and Multicultural Development 13(1 and 2): 83-102.

Thompson, C., O'Hare, G. and Evans, K. (1995) Tourism in The Gambia: Problems and proposals. Tourism Management 16(8): 571-581.

Todd, L. (1984) Modern Englishes: Pidgins and creoles. Oxford: Blackwell.

Vydrine, V. Bergman, T. G. and Benjamin, M. (2000) Mandé language family of West Africa: Location and genetic classification. SIL Electronic Survey Report. Dallas: SIL International.

VSO (2007) Personal communication from the media office. Voluntary Service Overseas.

Weil, P. M. and Saho, B. (2005) Masking for money: The commodification of Kankurang and Simba mask performances in urban Gambia. In S. Wooten (ed.) Wari Matters: Ethnographic explorations of money in the Mande world 162-177. Münster: Lit Verlag.

White Oyler, D. (2001) The era of Mande enlightenment. Mande Studies 3: 75-94.

Wright, D. R. (1981) Uprooting Kunta Kinte: On the perils of relying on encyclopedic informants. History in Africa 8: 205-217. 